\title{
On Malignant Change of Gastric Ulcer
}

\author{
By \\ Susumu Majima, Iwao Yamaguchi, Teiichi Teshima \\ and Katsumi Karube \\ From the Department of Surgery, Tohoku University School of Medicine, \\ Sendai; Directors: Prof. Emeritus M. Muto and Prof. T. Maki \\ and \\ Hisayuki Masuda \\ From the Department of Internal Medicine, Tohoku University \\ School of Medicine, Sendai; Director: Prof. S. Y a magata
}

(Received for publication, April 15, 1965)

\begin{abstract}
Although the concept of ulcer-carcinoma of the stomach, i.e., carcinoma arising from a pre-existing gastric ulcer, seems to have received significant support, it is still a matter in considerable dispute among pathologists and surgeons. The authors reviewed a total of 2,484 surgical specimens of the stomach which had been resected in the Tohoku University Hospital, and found probable evidence of early ulcer-carcinoma in 25 of them. These cases had typical chronic ulcer of the stomach and additional foci of early carcinoma - a single (two cases) or multiple (11 cases) small cancer foci in the mucosa of the ulcer margin, or a ring-shaped mucosal carcinoma involving the circumference of the ulcer (12 cases). The minute investigation of these early cases will greatly serve for the solution to the dispute mentioned above. This paper describes the histopathologic findings of these lesions and preoperative histories of the cases, and presents the authors' view in support of malignant change of gastric ulcer.
\end{abstract}

Since an advocation by Hauser ${ }^{1}$ from the histopathologic viewpoint, the development of carcinoma from pre-existing gastric ulcer has been accepted as a fact by an increasing number of pathologists. The present authors have also been interested in this problem from the medical and surgical points of view and one of them (S.M.) already published a series of reports in support of the malignant change of gastric ulcer. ${ }^{2-4}$ On the other hand, however, a considerable number of authors, especially those of the United States of America, still claim that the gastric ulcer rarely or never undergoes a malignant change. Until recently, the concept of ulcer-carcinoma of the stomach was generally approved in Japan and rarely was the subject of controversy. But, with the recent exchange of information between the American and the Japanese medical sciences, it appears that some Japanese researchers have also become suspicious of malignant change of gastric ulcer.

間島 進, 山口 藤, 手島貞一, 軽部克己, 增田久之 
The solution to this problem may demand a thorough histopathologic study of the lesions consisting of a typical chronic gastric ulcer and foci of early carcinoma around it, as well as a long-term follow-up of the clinical cases bearing chronic gastric ulcers. As a contribution to this problem, this paper depicts the results of histologic and clinical studies of early gastric carcinomas associated with chronic ulcers which the present authors encountered at the Tohoku University Hospital.

\section{MATERIALS AND METHODS}

During the last 23 years, a total of 2,484 stomach resections were performed at the Surgical Department of the Tohoku University Hospital, under the diagnosis of gastric carcinoma or gastric ulcer. In 25 stomach specimens of this series, a typical chronic peptic ulcer, as manifested by a complete discontinuation of the muscular coat of the stomach with its free ends bent upward into the ulcer margin, downward curling of the lamina muscularis mucosae and replacement of the ulcer base by callous omental tissue, was associated with evidence of early malignant growths in the mucosa of the ulcer margin. These 25 cases constitute the basis of this study.

In these specimens, the ulcer lesion was cut through into 10-45 consecutive blocks, a large number of histologic slides or even serial sections, when appeared to be necessary, were prepared from each of the blocks, and the structure of the lesion was thoroughly investigated. Moreover, a retrospective follow-up of the preoperative history was made in all these cases for clinical manifestation of preexisting peptic ulcer.

\section{RESULTS}

\section{Distribution of malignant foci around ulcer}

The diagrams shown in Fig. 1 schematically represent the site and extent of cancer foci recognized in the present cases.

In Cases 1 and 2, a single, small focus of carcinoma with partial infiltration to the submucosa, such as shown in Fig. 2, was identified in a quite limited area of the mucosa of the ulcer margin.

In the eight cases from Case 3 to Case 10, three to eight small cancer foci were recognized on or adjacent to the ulcer margin. These cancer lesions were superficial, being limited within the mucosa (Fig. 3) or only slightly infiltrating to the submucosa, and were separate from each other as confirmed by examination with serial blocks and, in part, serial sections. Moreover, it may be worth particularly mentioning that among three cancer foci identified on the ulcer margin of Case 5, two were carcinoma solidum simplex and the other was adenocarcinoma.

In the three cases from Case 11 to Case 13, a principal cancer focus occupied a considerably large portion of the ulcer margin and involved the mucosa and 


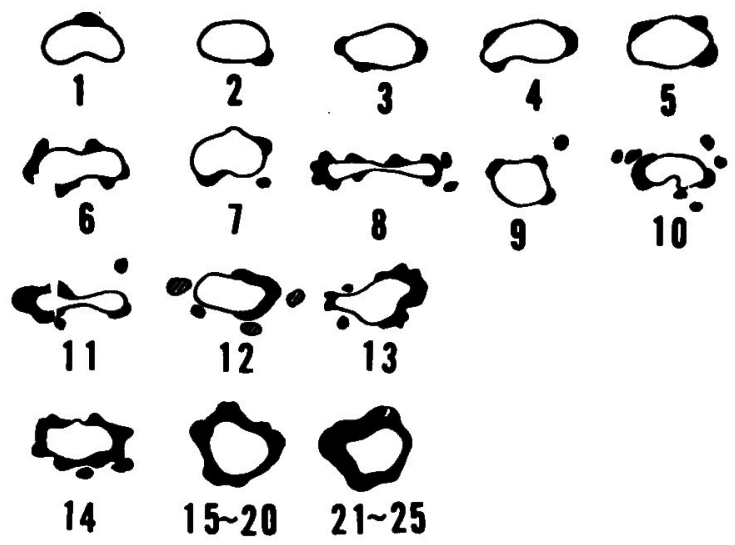

Fig. 1. Diagrams representing the site and extent of malignant foci identified on and beside the margins of gastric ulcers. Shaded areas in Case 12 indicate pre-cancerous lesions.

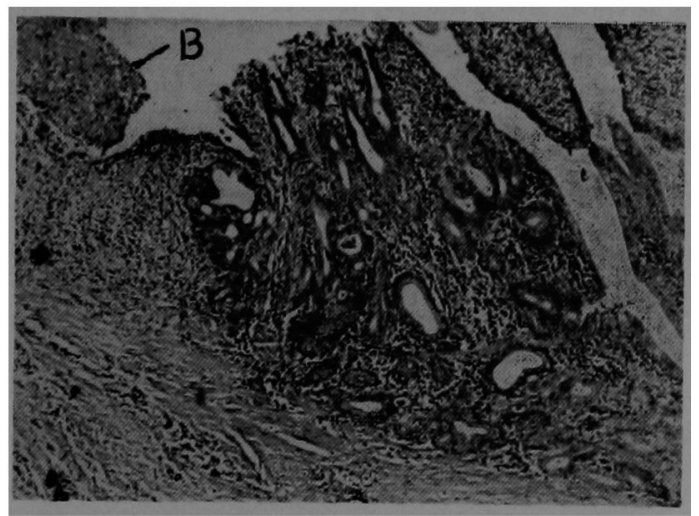

Fig. 2. A single, microscopic focus of adenocarcinoma recognized on the margin of a gastric ulcer. $B$ indicates the base of the ulcer. The ulcer was a typical chronic ulcer as evidenced by complete abruption of the muscular coat and, as seen in this picture, remarkable proliferation of connective tissue beneath the ulcer base. $\mathrm{H}$ and $\mathrm{E}$ stain, $\times \mathbf{4 0}$.

submucosa. Besides such a main focus, a number of small, separate cancer foci, all being limited to the mucosa, were identified on or around the ulcer margin in all the cases of this group. The ulcer of Case 12 was further associated with three areas of remarkable epithelial overgrowth, as indicated in Fig. 1 as shaded areas, which might probably represent pre-cancerous conditions.

In the remaining 12 cases from Case 14 to Case 25, the cancer lesion almost completely or completely involved the circumference of the ulcer. Even in this 


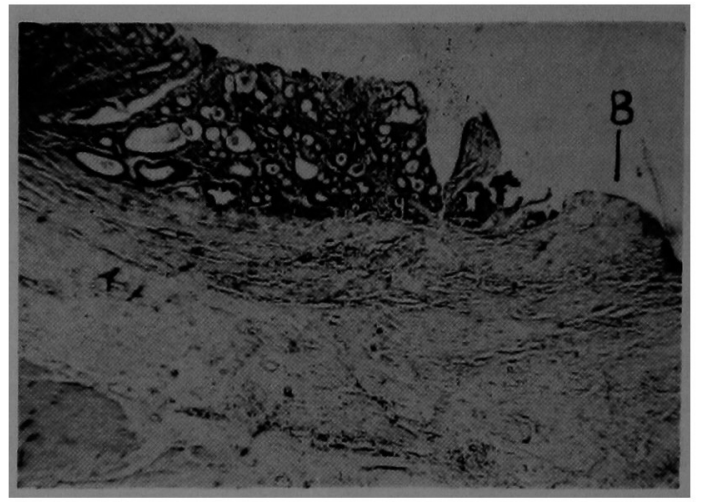

Fig. 3. A small cancer focus seen at a point of the margin of a chronic gastric ulcer. $B$ indicates the base of the ulcer. The malignant growth in this case was confined within the mucosal layer of the ulcer margin. $H$ and $E$ stain, $\times 30$.

group, however, the cancer lesions of Cases 14 through 20 were uneven in their widths, being constricted at several sites, and appeared to be the lesions formed by fusion of once separated, multiple cancer foci. In Case 14, moreover, two additional small foci of carcinoma were recognized a little apart from the ring-like cancer lesion on the margin of the ulcer.

\section{Histopathologic findings of the cancer foci recognized on the ulcer margin}

In Cases 1 to 10 in which single or multiple small cancer foci were observed on the ulcer margin, the gastric mucosa adjoining to the ulcer margin generally

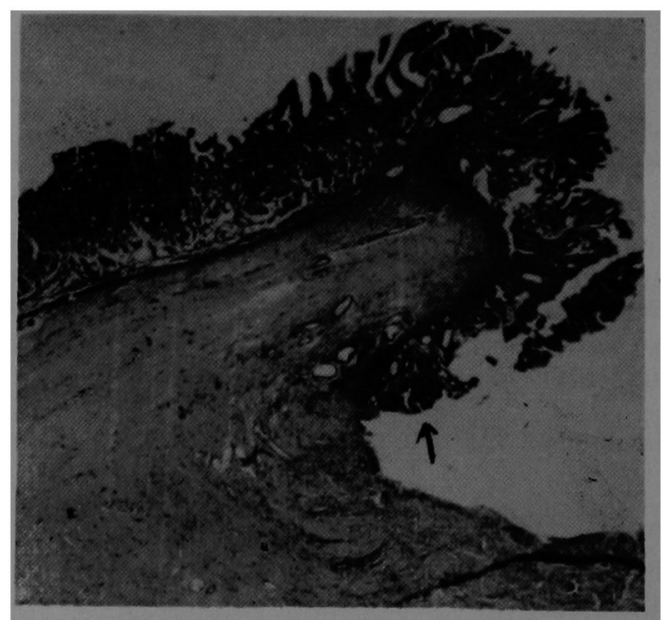

Fig. 4. A focus of early carcinoma (arrowed) identified in atypically proliferated gastric mucosa of the margin of a chronic ulcer. $\mathrm{H}$ and $\mathrm{E}$ stain, $\times 10$. 


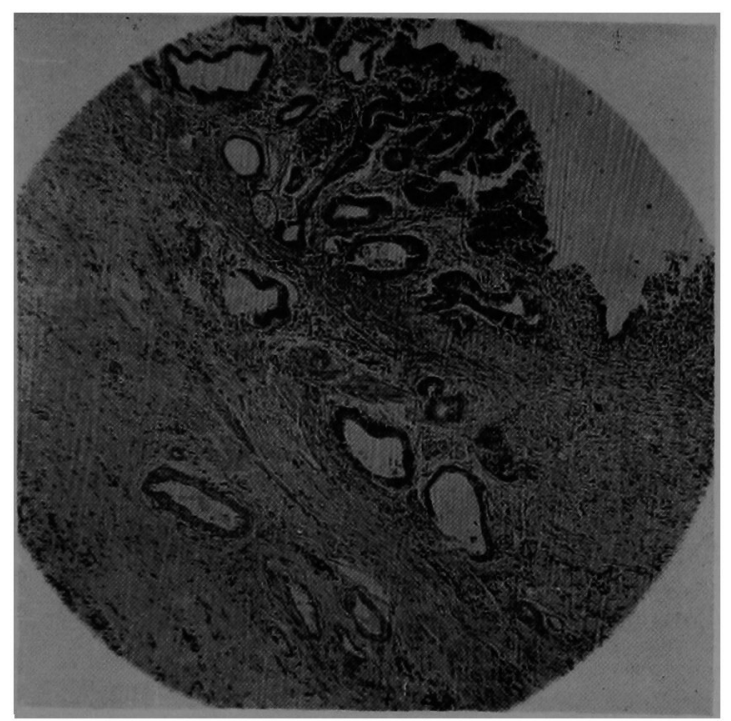

Fig. 5. Higher magnification $(\times 100)$ of the arrowed portion of Fig. 4. Atypical cells constitute a lesion of adenocarcinoma exhibiting nests and acini of various shapes and sizes.

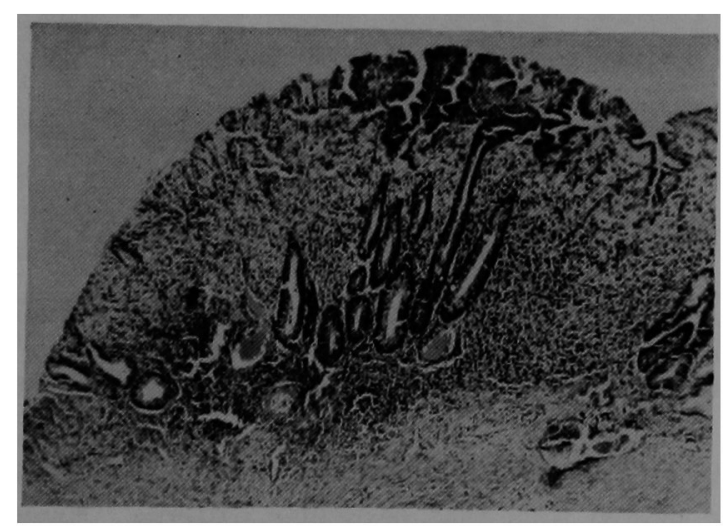

Fig. 6. A vary small focus of carcinoma solidum identified in the superficial layer of atypically proliferated mueosa at the margin of an ulcer. $H$ and $E$ stain, $\times 40$.

exhibited fairly distinct atypical proliferation even in non-cancerous areas. And in seven of these cases (Cases 1, 2, 3, 4, 7, 9 and 10), the cancer foci were located in the areas of atypical mucosal proliferation as shown in Fig. 4. The malignant lesions of these cases consisted of atypical cells having large, chromatin-rich nuclei and, as seen in Fig. 5, exhibited irregular cell-nests or irregular glandular structures. The cancer foci on the ulcer margins of the other cases of this group 


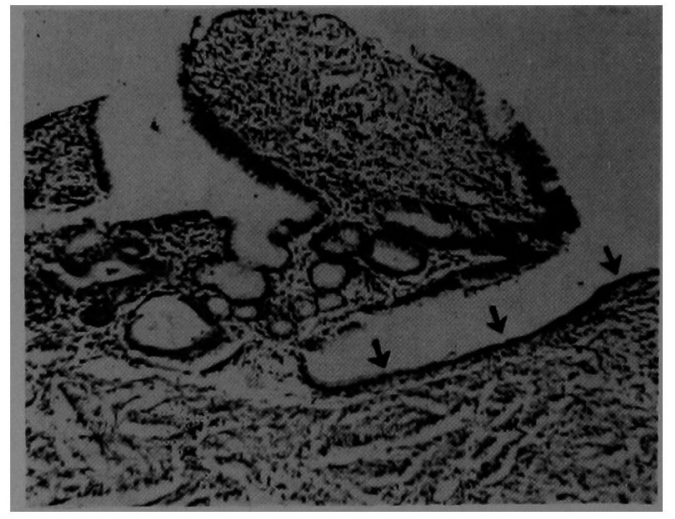

Fig. 7. Atypically proliferated, regenerated gastric mucosa at the margin of a chronic ulcer. Arrows indicate the regenerated epithelium extending into the base of the ulcer. $H$ and $E$ stain, $\times 100$.

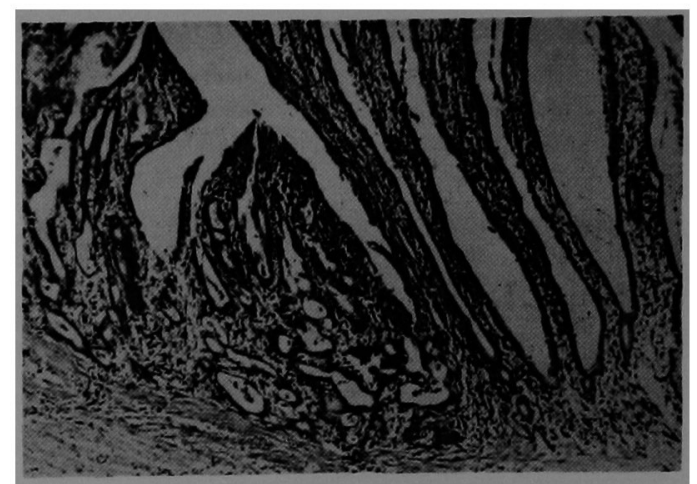

Fig. 8. A small focus of adenocarcinoma identified in the regenerated mucosa of the ulcer margin showing remarkable papillary proliferation. $\mathrm{H}$ and $\mathrm{E}$ stain, $\times 100$.

(Cases 5, 6 and 8) were also recognized in the atypically proliferated areas of the mucosa, but they showed somewhat particular patterns. Namely, the lesions of Cases 6 and 8 were foci of carcinoma solidum simplex which were, as seen in Fig. 6, made up of polymorphous, strongly anaplastic cells including signet ring cells at a large proportion. In Case 5, two of a total of three cancer foci were those of carcinoma solidum simplex as in the above two cases, but the remaining one was adenocarcinoma consisting of high-columnar cells, as was referred to before.

Thus, the small cancer foci on the ulcer margins of these cases were all identified to be those developing in the atypically grown mucosae. In this relation, it was noted in Cases 2, 3, 4, 7 and 8 that a layer of regenerated epithelium extended, at several sites, from the atypically proliferated mucosa of the ulcer margin toward the 


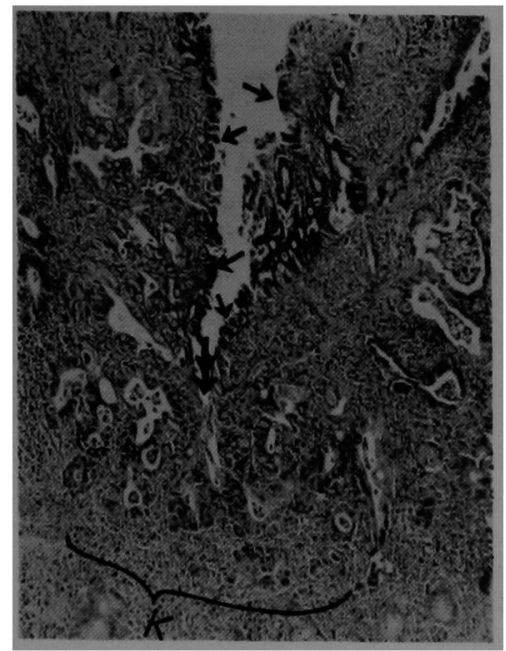

Fig. 9. A circumscribed focus of carcinoma $(K)$ recognized on the margin of a gastric ulcer. Note that the malignant focus is connected to the regenerated epithelium of gastric mucosa (arrowed) at the portion indicated by a double arrow. $H$ and $E$ stain, $\times 100$.

base of the ulcer. The structure of such regenerated epithelium was occasionally quite abnormal, forming irregular acini of various sizes and shapes (Fig. 7). Moreover, three of these cases (Cases 3,4 and 7) included one each very small cancer focus that was localized within such regenerated mucosa (Fig. 8); in such a site, highly irregular acini which were lined by very anaplastic, regenerated epithelia were connected to each other by processes of cell-nests and thus formed an apparent focus of adenocarcinoma. Furthermore, as shown in Fig. 9, examination by serial sections of such a lesion gave a quite remarkable finding that the cancer focus of this type was connected to the regenerated epithelial lining of the mucosa by a very narrow band of cells.

3. Histopathologic findings of the cancer foci recognized in the perimarginal area of the ulcer

The eight cases from Case 7 to Case 14 had one or more small cancer foci in the gastric mucosa somewhat distant from the respective ulcer margins, besides the main lesions on the latter (cf. Fig. 1). Most of these perimarginal cancer foci were quite adjacent to the ulcer margin, the distance being about $1 \mathrm{~cm}$ or less, but a focus observed in Case 9 and some of the lesions in Cases 10 and 11 were $2.5-3.0 \mathrm{~cm}$ distant from the ulcer margin.

The former lesions, i.e., the cancer foci lying near the ulcer margin, were all situated in the atypically proliferated mucosae which extended to the perimarginal areas, and coincided in the histologic feature with the main cancer focus of respective 


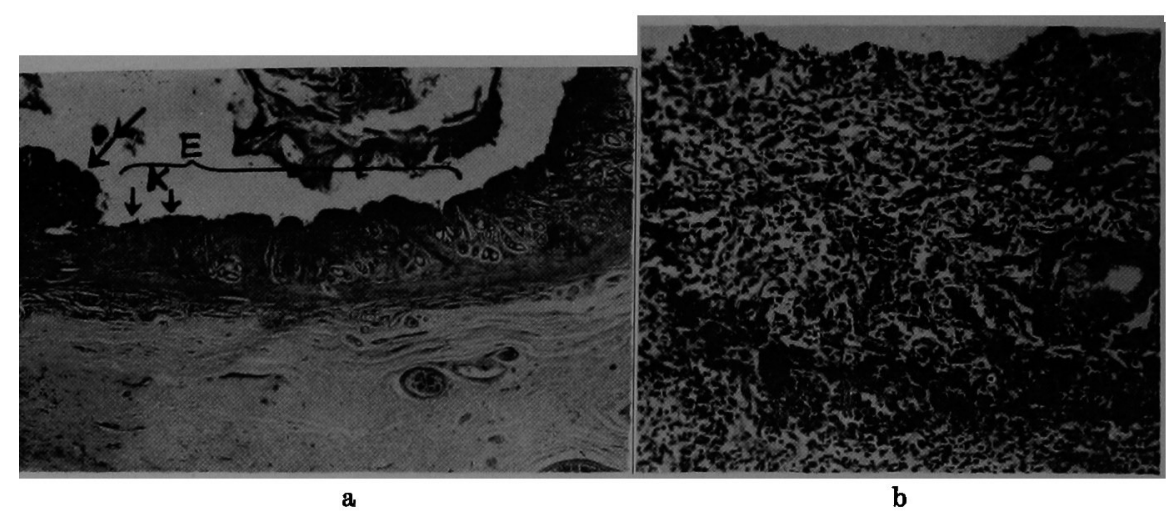

Fig. 10. a, a small cancer focus $(K)$ identified in an erosive lesion $(E)$ that was situated a little apart from the margin of a chronic gastric mucosa. H and $\mathbf{E}$ stain, $\times 10$. $b$ is a higher magnification $(\times 100)$ of the focus $K$.

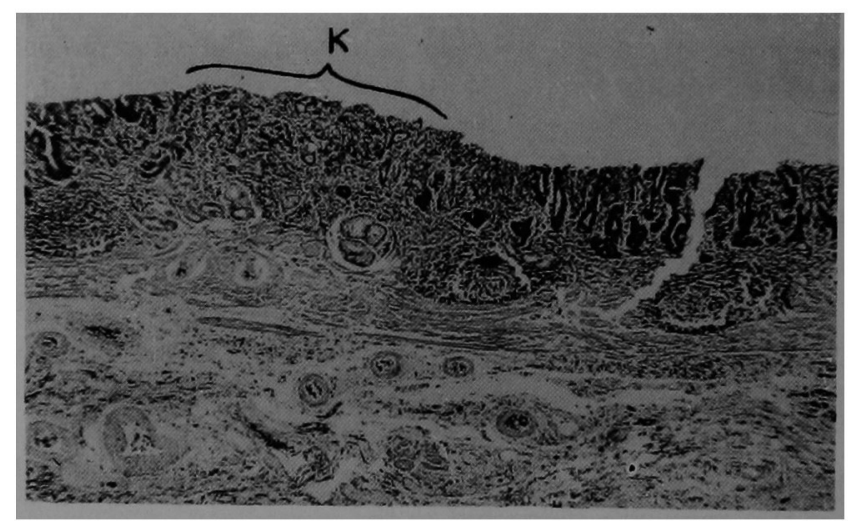

Fig. 11. A focus of carcinoma $(K)$ recognized somewhat apart from the margin of a chronic gastric ulcer in the gastric mucosa with remarkable evidence of atrophic gastritis. $H$ and $\mathbf{E}$ stain, $\times 30$.

cases. In some instances, however, these perimarginal foci were accompanied with an erosion that showed epithelial regeneration at its margin (Fig. 10), or with a shallow ulcer whose infiltration was limited to a part of the muscularis mucosae at most.

On the other hand, the three cases having cancer foci that were quite distant from the ulcer margin all showed remarkable evidence of chronic atrophic gastritis over an area including the antrum and body of the stomach. Such atrophic gastritis was particularly prominent in the portion surrounding the ulcer, as manifested by an almost complete disappearance of proper gastric glands, proliferation of interglandular connective tissue and an irregular glandular structure 
of the foveolar epithelium, and the distant cancer foci were all situated in such highly atrophic mucosa. In these cancer foci, the glandular structure was completely lost and was replaced by network or nests of atypical epithelial cells, as shown in Fig. 11.

\section{Clinical course before operation}

All but one of the 25 cases of this series previously had some gastric com-

TABLE I. Duration of Ulcer Symptoms

\begin{tabular}{c|c}
\hline Duration (years) & No. of cases \\
\hline Less than 1 & 3 \\
$1-2$ & 4 \\
$2-3$ & 4 \\
$3-5$ & 3 \\
5 or more & 10 \\
\hline Total & 24
\end{tabular}
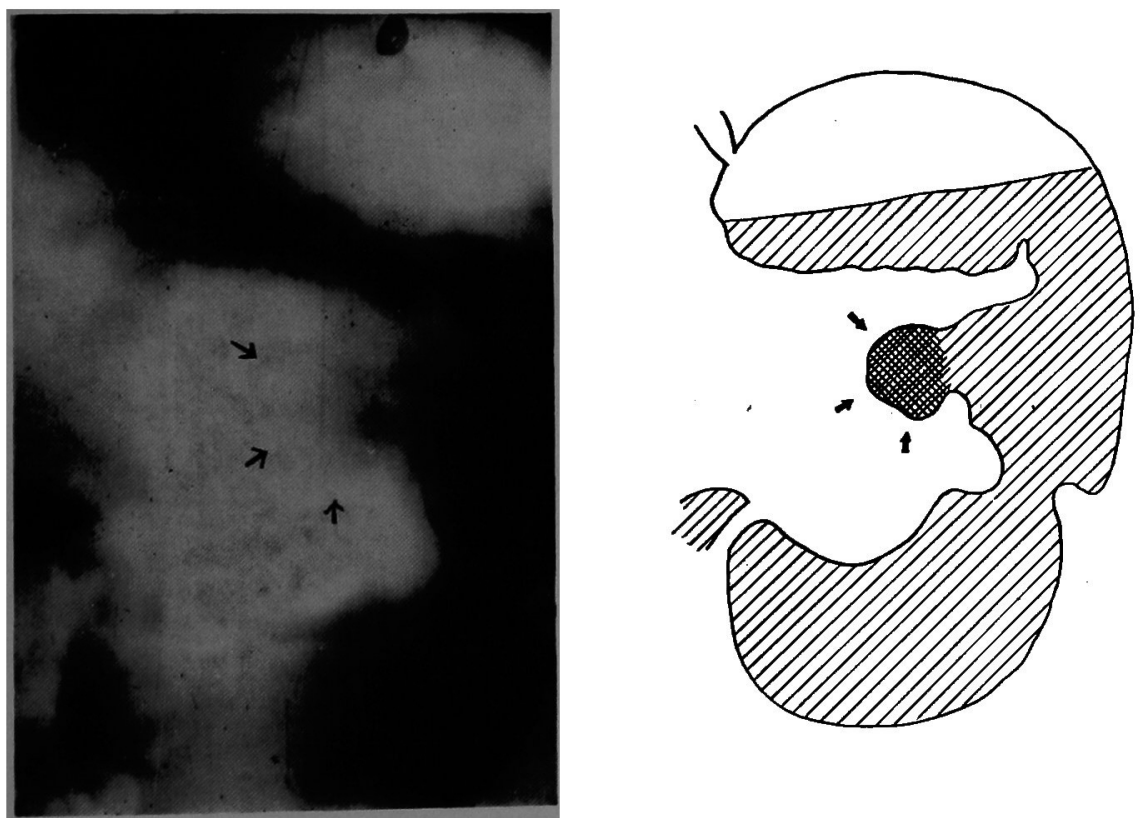

Fig. 12. Case 5. Roentgenogram of the stomach taken two years before operation. A large niche (arrowed) which is suggestive of a walledoff perforated ulcer is seen on the lesser curvature of the gastric body. This case was treated in the war time where the $x$-ray picture was often recorded immediately on printing paper for shortage of the x-ray film. In this and the next figures, schematic line drawings are shown in compensation for the poorly contrasted roentgenograms. 

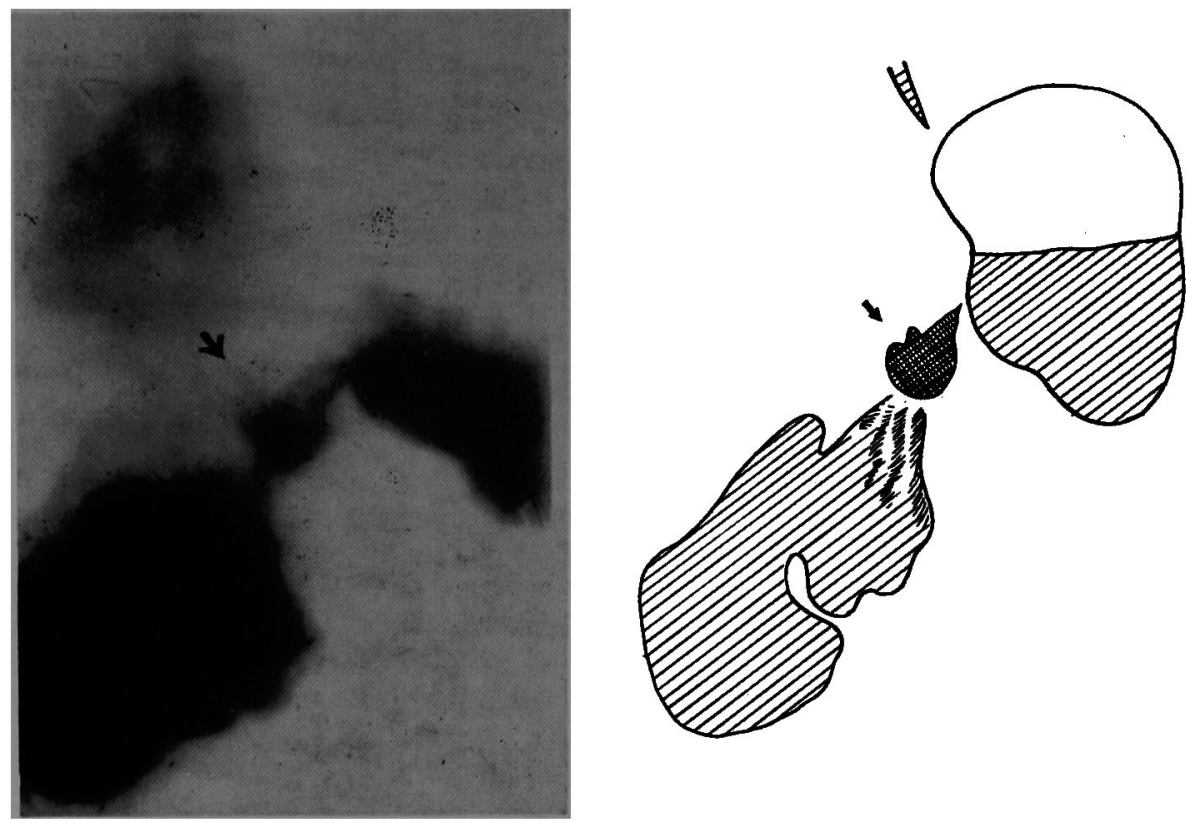

Fig.:13. Later aspect of the same niche (arrowed) showing recurrence of the ulcer after a period of remission by medical treatments. The stomach exhibits hour-glass deformity.

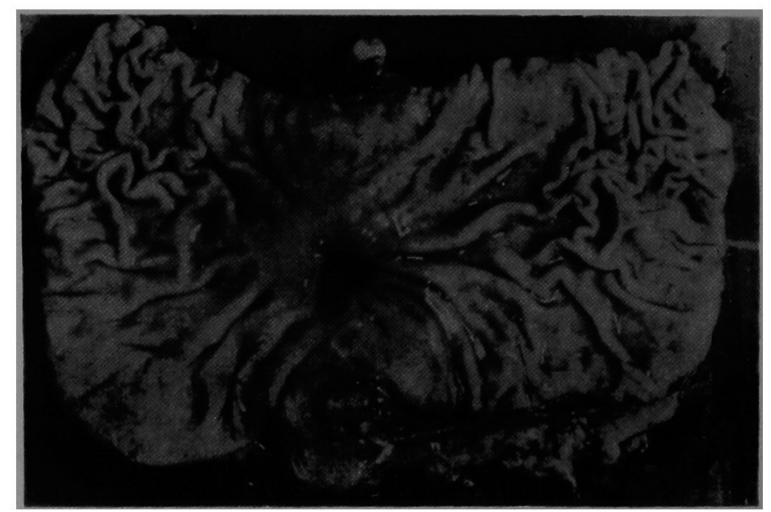

Fig. 14. Surgical specimen of the same case showing a walled-off perforated chronic ulcer on the lesser curvature.

plaints and were seen in hospitals, the exceptional one case being a patient screened by mass examination of the stomach. The duration since onset of the symptoms till operation, in the 24 cases excluding the asymptomatic one, is summarized in Table I. Seventeen among the $\mathbf{2 4}$ cases had gastric complaints for two years or more 


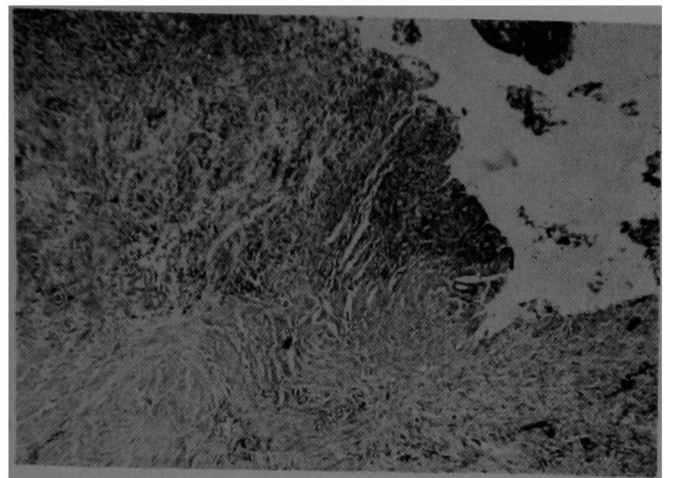

Fig. 15. Photomicrogram of one of a total of three cancer foci recognized on the margin of the gastric ulcer of Case 5. H and $\mathrm{E}$ stain, $\times 30$.

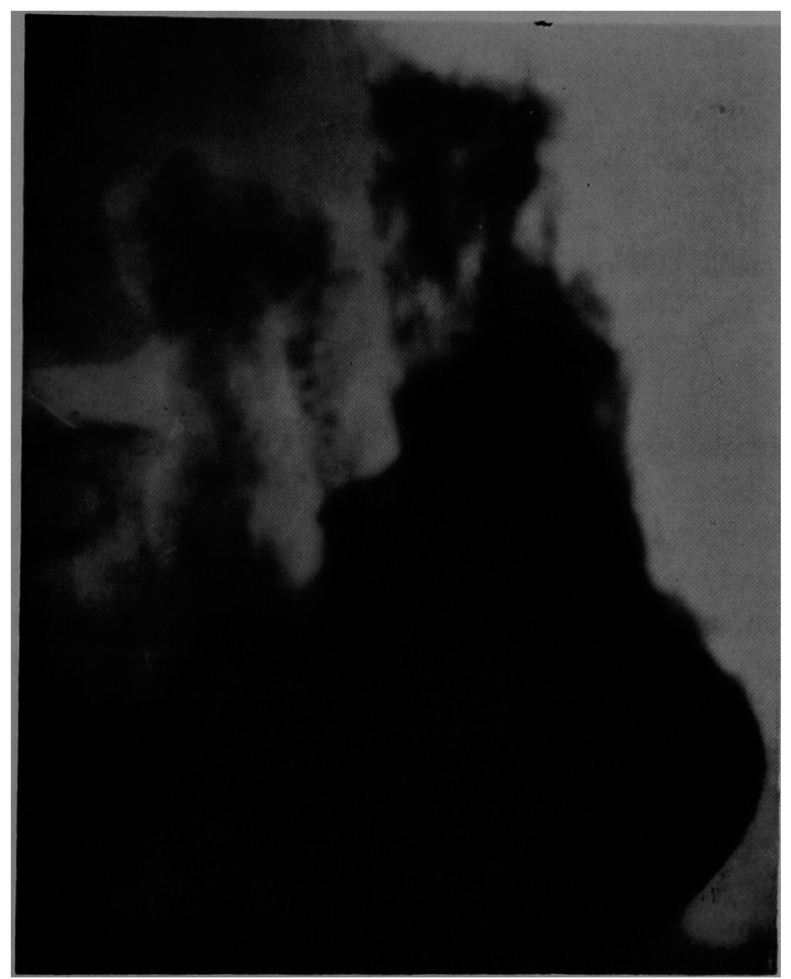

Fig. 16. Case 7. Roentgenogram of the stomach taken three and a half years before operation. A typical ulcer niche is observed at incisura angularis. 


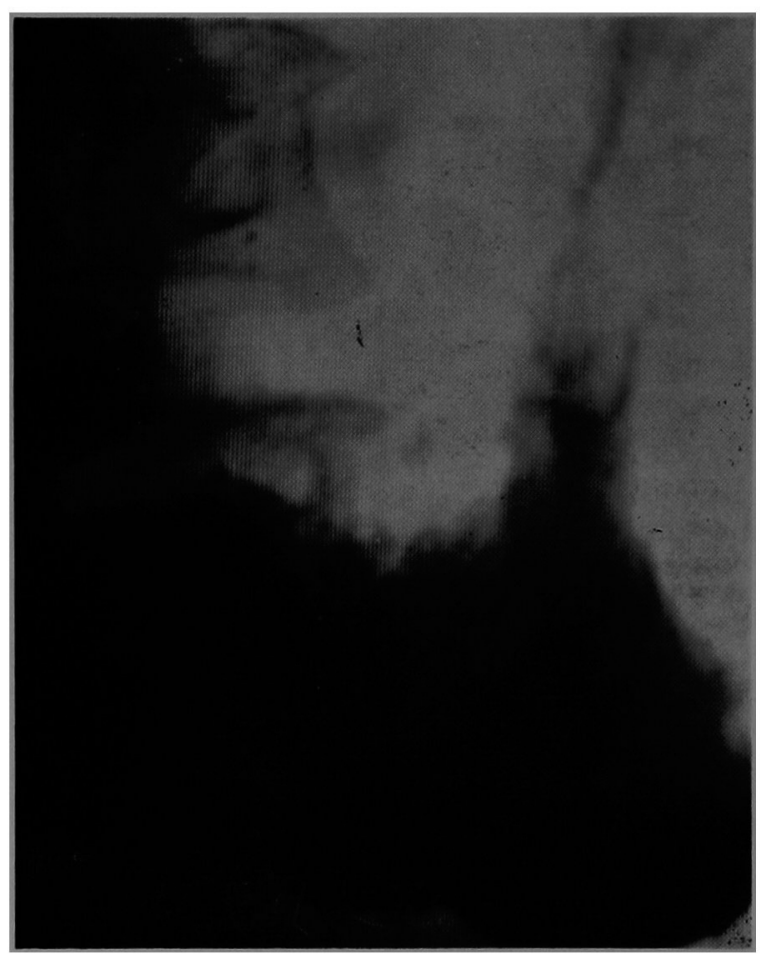

Fig. 17. Aspect of the same niche showing a significant improvement gained by two months' medical treatments.

prior to operation; all these cases initially had typical ulcer symptoms and were since treated medically, under the diagnosis of peptic ulcer, with intermittent remission of the symptoms. These cases included the four patients (Cases 5, 7, 8 and 21) who had been followed up as gastric ulcer cases for two to six years, before operation, at the Department of Internal Medicine, Tohoku University Hospital. The histories of these cases are briefly reviewed in the following.

Case 5, a 54-year-old male. Six years ago the patient started to complain of ulcer symptoms and was treated at a clinic with remission of the symptoms. But the symptoms again appeared two years ago and he was admitted to the Department of Internal Medicine of the Tohoku University Hospital. The X-ray study on admission revealed a fairly large niche on the lesser curvature of the gastric body which was suggestive of a penetrating ulceration (Fig. 12). Medical treatments at that time were followed by a considerable relief of the objective as well as the subjective symptoms and he was discharged after two months. However, the same symptoms frequently recurred thereafter, the niche again became manifest (Fig. 13) and the patient was therefore re-admitted to the Hospital for 


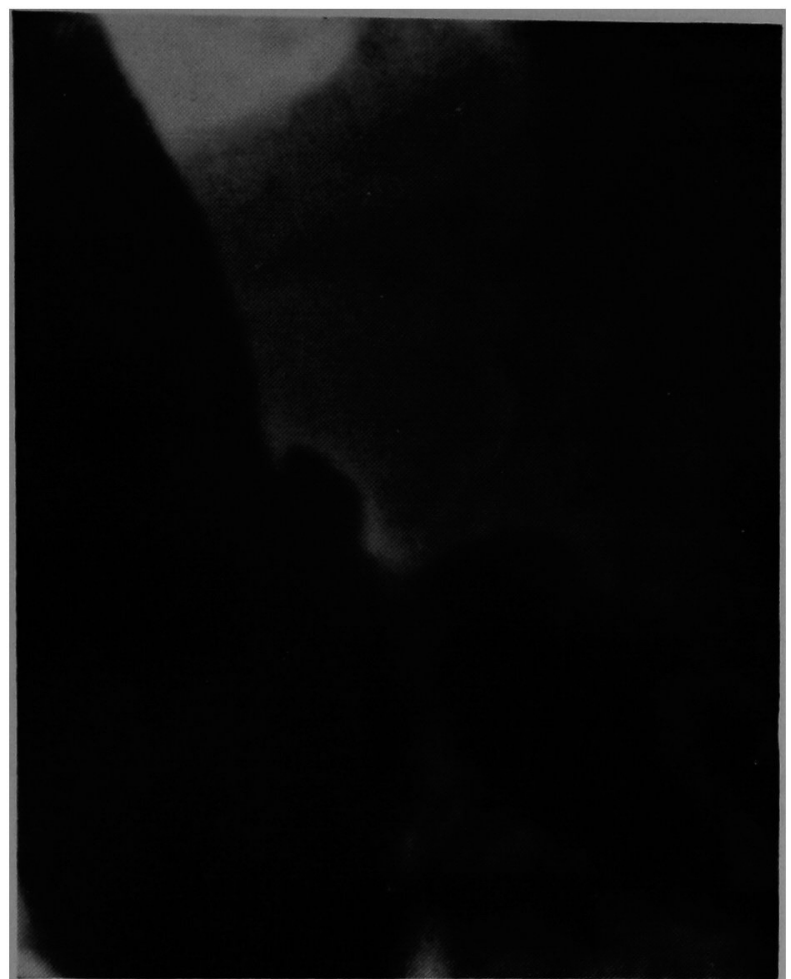
ulcer.

Fig. 18. Film of the same case showing recurrence of the gastric

surgical treatment. The resected specimen had a walled-off perforated ulcer on the lesser curvature of the gastric body (Fig. 14), the margin of which included three microscopic foci of carcinoma (Figs. 1 and 15).

Case 7, a 58-year-old male. About six years ago he started to perceive a hunger pain in the epigastrium and three and a half years ago he was admitted to the Department of Internal Medicine for an episode of hematemesis. The X-ray examination indicated the presence of an ulcer niche at the incisura angularis, as shown in Fig. 16. After two months' medical treatment, the niche significantly diminished in size (Fig. 17) and the ulcer symptoms became less remarkable, and the patient was discharged. However, he was later re-admitted to the Department for a recurring epigastric pain and additional gastric discomfort. Recurrence of the niche was demonstrated on X-ray examination (Fig. 18) and the ulcer was bleeding as manifested by attacks of hematemesis and melena. Stomach resection was performed at the Surgical Department, which revealed a chronic callous ulcer at the middle of the lesser curvature (Fig. 19). On histologic examination of the specimen, a total of three cancer foci were identified on the margin 


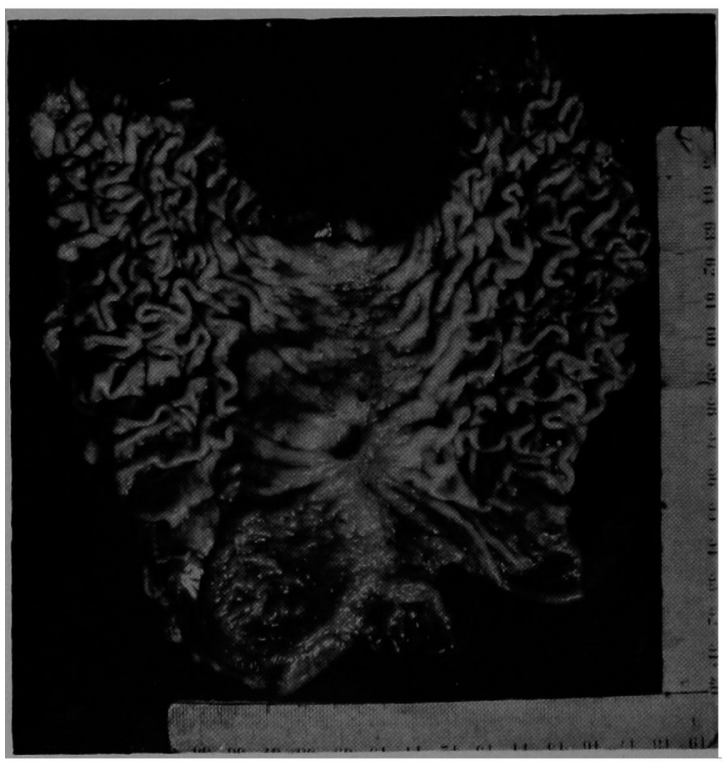

Fig. 19. Surgical specimen of the same case. A chronic gastric ulcer is seen at the middle of the lesser curvature.

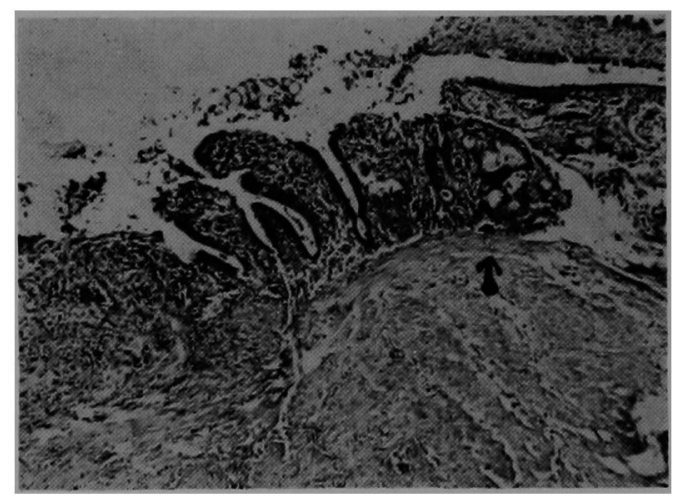

Fig. 20. A small cancer focus (arrowed) identified in the regenerated gastric mucosa at the margin of the gastric ulcer of Case 7. $\mathbf{H}$ and $\mathbf{E}$ stain, $\times 30$.

of the ulcer and in an area a little distant from the ulcer margin (Figs. 1 and 20).

Case 8, a 53-year-old male. He had complained of a characteristic ulcer pain for five years. Three years ago, he was admitted to the Department of Internal Medicine for the above complaint, and a fairly large niche on the lesser curvature of the gastric body was revealed by X-ray study (Fig. 21). After two months' treatment, the patient left the Department with an improvement of the symp- 


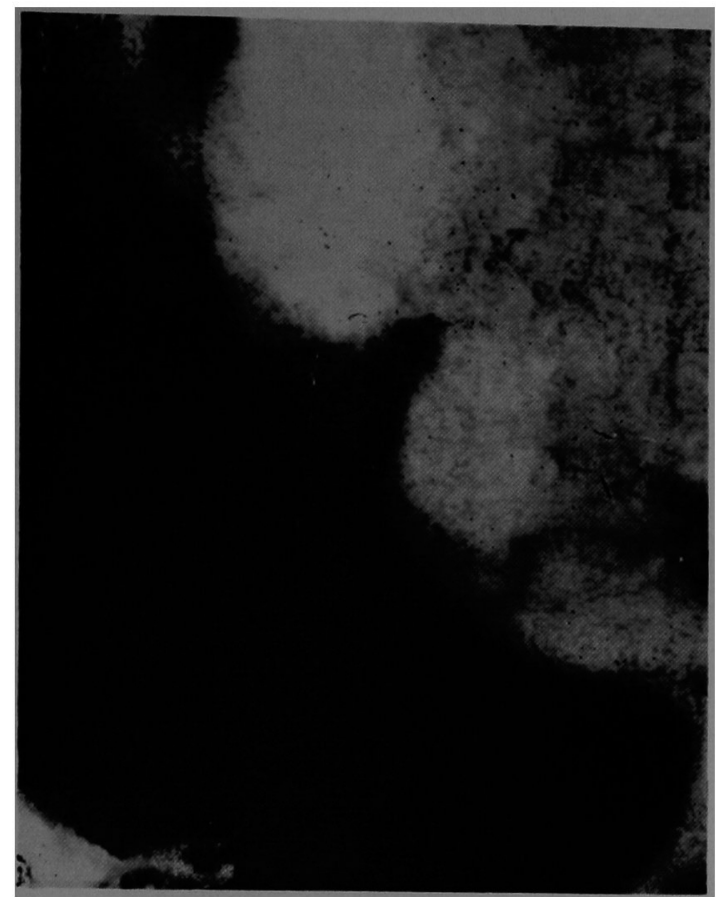

Fig. 21. Case 8. Roentgenogram of the stomach taken three years before operation. A large niche is seen on the lesser curvature.

tom but not with a complete disappearance of the niche. After a while, he again started to perceive a hunger pain which became severer in recent days. A marked contraction of the lesser curvature of the stomach and a niche suggestive of a linear ulcer in the gastric body were revealed at this time roentgenographically (Fig. 22), and the patient was operated on. The resected stomach had a linear ulcer with remarkable evidence of epithelial regeneration (Fig. 23) and the margin of the ulcer contained multiple, small foci of carcinoma (Figs. 1 and 6).

Case 21, a 60-year-old male. About seven years ago, he was seen in the Department of Internal Medicine, with a chief complaint of epigastric pain in hunger, and an ulcer niche was detected on the lesser curvature of the gastric body (Fig. 24). Remarkable improvements of the symptom and of the roentgenographic evidence of gastric ulcer were attained by three months' medical treatment during admission, and he was discharged from the Department. The patient thereafter was in good health until one year ago when he again started to complain of ulcer symptoms. The $\mathrm{X}$-ray study at that time revealed two adjoining niches in the same portion of the stomach as in the previous study (Fig. 25). The niches became considerably smaller after a period of medical treatment but, at the same time, abruption of convergent rugal folds became manifest around them. Two 


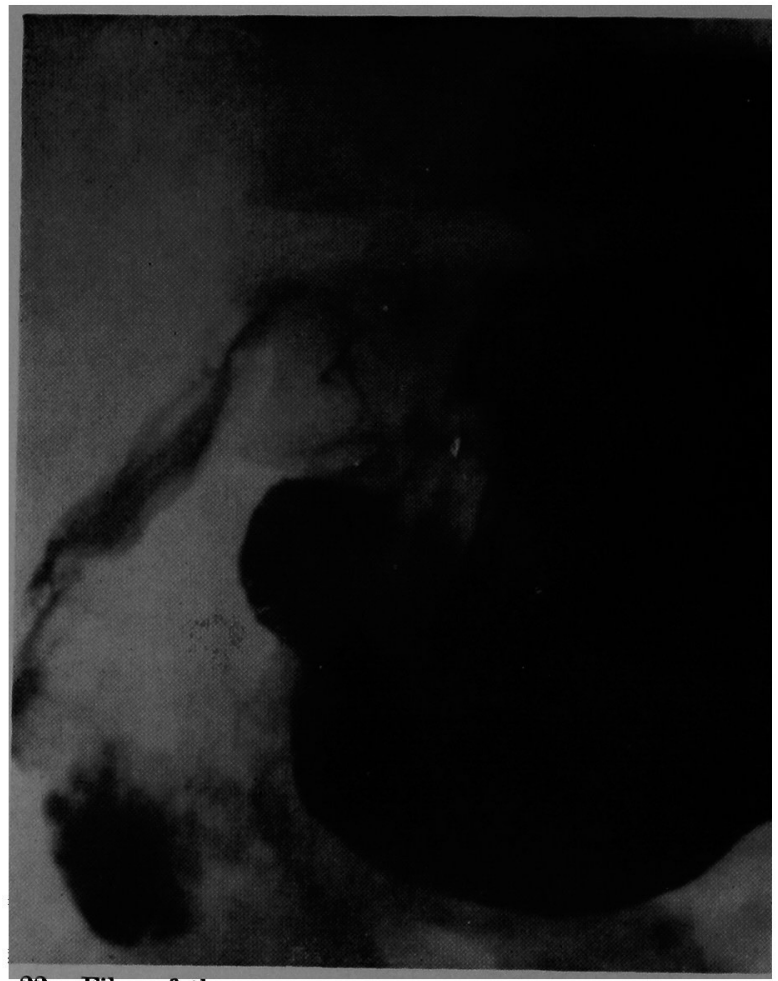

Fig. 22. Film of the same case taken shortly before operation. The markedly contracted lesser curvature of the stomach exhibits a niche that is suggestive of a linear ulcer.

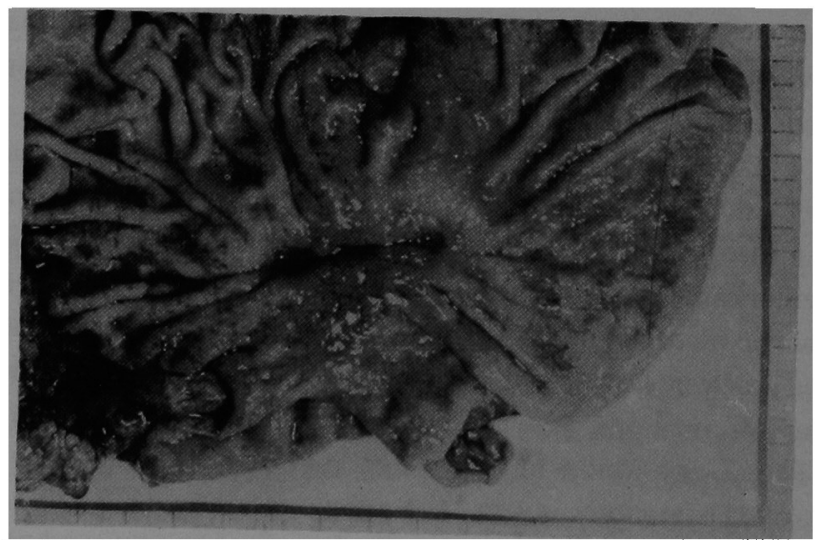

Fig. 23. Photogram of the surgical specimen of Case 8 showing a linear ulcer of the stomach. 


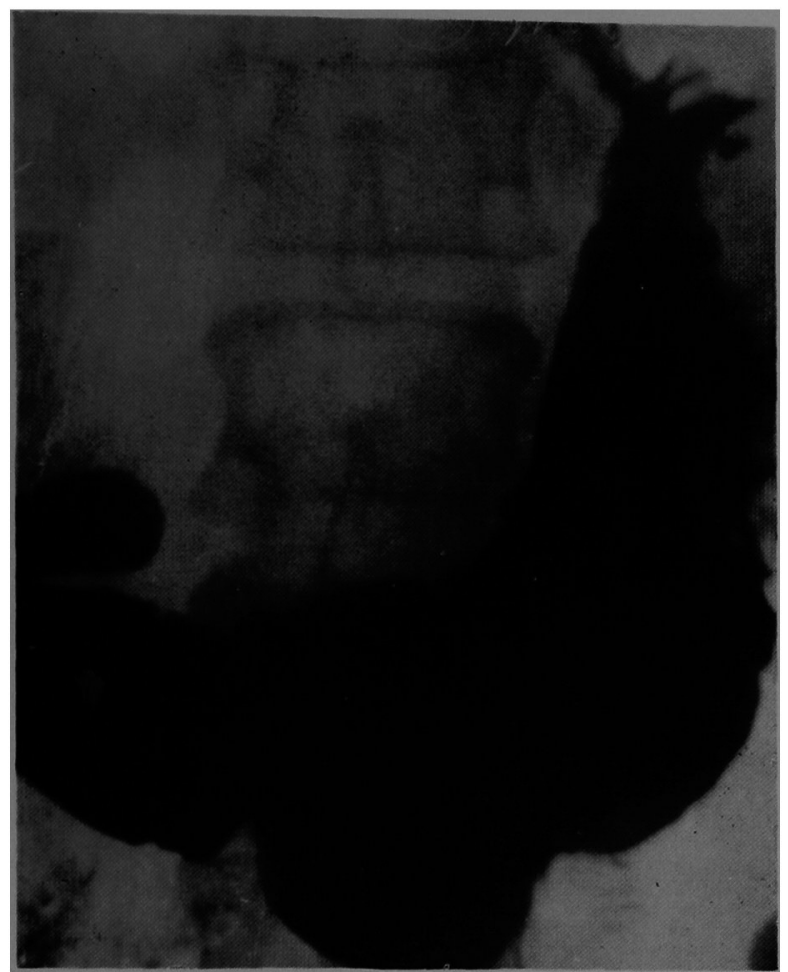

Fig. 24. Case 21. Roentgenogram of the stomach taken about seven years before operation. An ulcer niche is seen on the lesser curvature.

months later, filling defects were noted about the niches (Fig. 26) and exfoliative cytology was suggestive of malignancy. The patient therefore underwent stomach resection and a linear ulcer was found on the lesser curvature of the gastric body (Fig. 27). Histologically, the ulcer was a chronic callous ulcer with significant evidence of healing with scar (Fig. 28), and the regenerated epithelium around the ulcer margin was found to have been almost entirely replaced by carcinomatous tissues (Figs. 1 and 29).

\section{DISCUSSION}

The histopathologic concept of ulcer-carcinoma of the stomach, i.e., a carcinoma produced by malignant change of gastric ulcer, goes back to the detailed work of Hauser (1926) who proposed the following two conditions as the pathologic requirements in the diagnosis of ulcer-carcinoma: (1) the ulcer in question should be a typical chronic ulcer characterized by complete discontinuation of the muscular coat of the stomach, and (2) carcinomatous foci should be confined to the margin of the ulcer without infiltration to the base of the ulcer. ${ }^{1}$ Although such a 


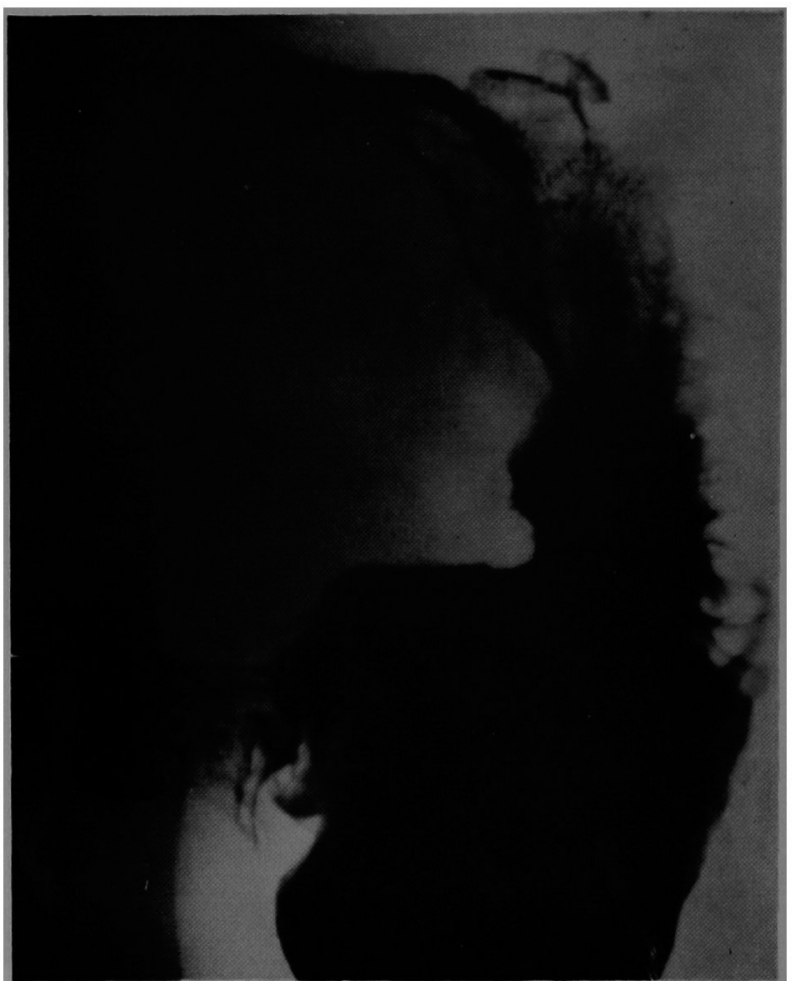

Fig. 25. Film of the same case taken one year before operation when ulcer symptoms again started to appear. Two adjoining niches are seen on the lesser curvature.

concept has got support from most of subsequent researchers, it has also evoked opposition of not a few authors ${ }^{5-9}$ who believe that not all the lesions which meet the Hauser's criteria are ulcer-carcinomas because a similar condition would also result from secondary, peptic ulceration of primary carcinoma. Thus, the opinion is still not unequivocal among pathologists as to the origin of the lesion consisting of a chronic gastric ulcer and cancer foci on its margin.

Needless to say, the discussion on this subject should be based on the examination of gastric ulcers with apparently early, malignant lesions. In other words, it is hardly possible, in general, to identify the origin of an advanced carcinoma, and such an effort would produce nothing more than confusion. The authors' materials consisted of 25 selected cases in which cancer foci were confined within the mucosa, or the mucosa and submucosa, of the ulcer margins or perimarginal areas, thus being adequate to the present purpose. From the histopathologic findings of these cases, the following three facts of interest may be pointed out.

The first is a characteristic feature of the small cancer foci that were recognized 


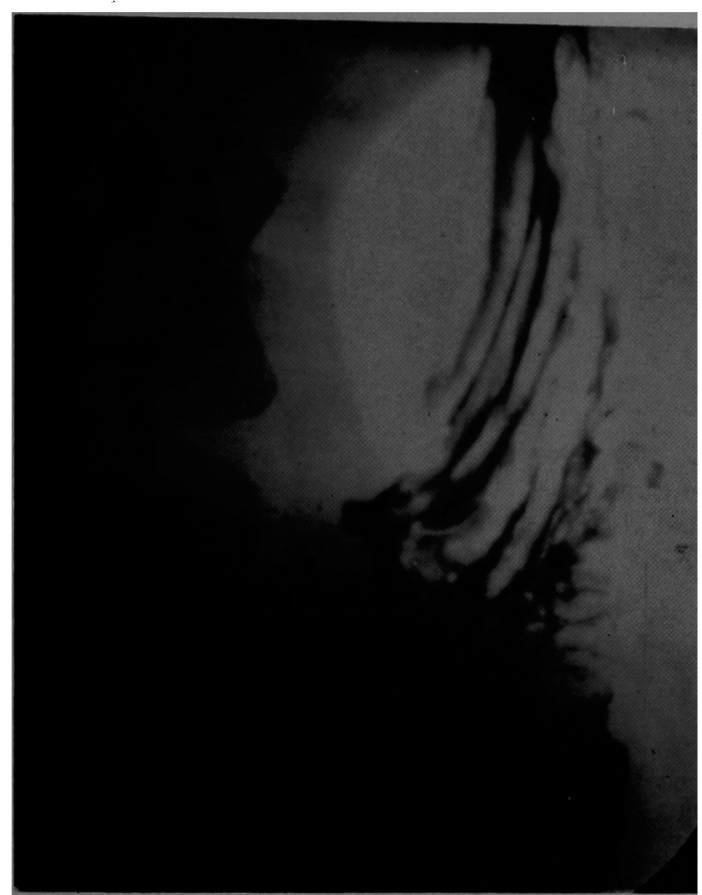

Fig. 26. Film of the same case taken after a period of medical treatments. Filling defects are noted around the niche.

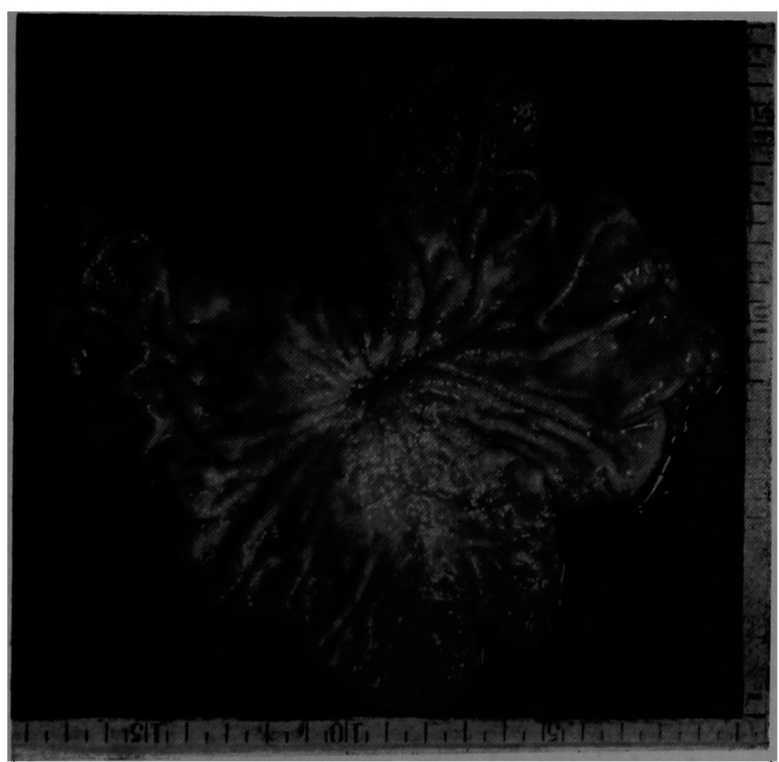

Fig. 27. Surgical specimen of the same case. A linear gastric ulcer is seen on the lesser curvature. 


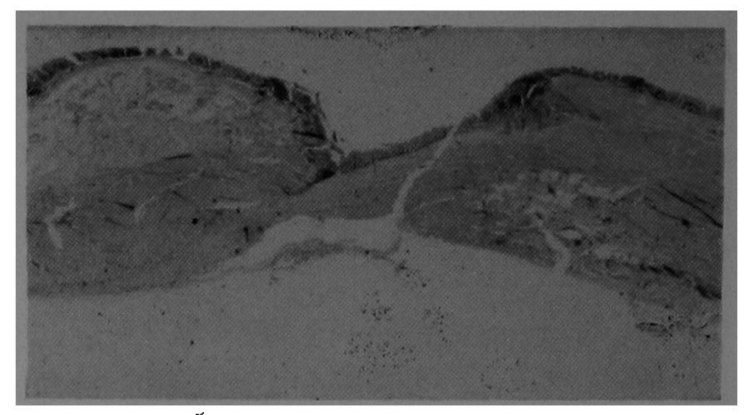

Fig. 28. Low magnification photogram $(\times 3)$ of a section of the ulcer of the same case, showing an almost complete healing with scar tissue. $\mathrm{H}$ and $\mathrm{E}$ stain.

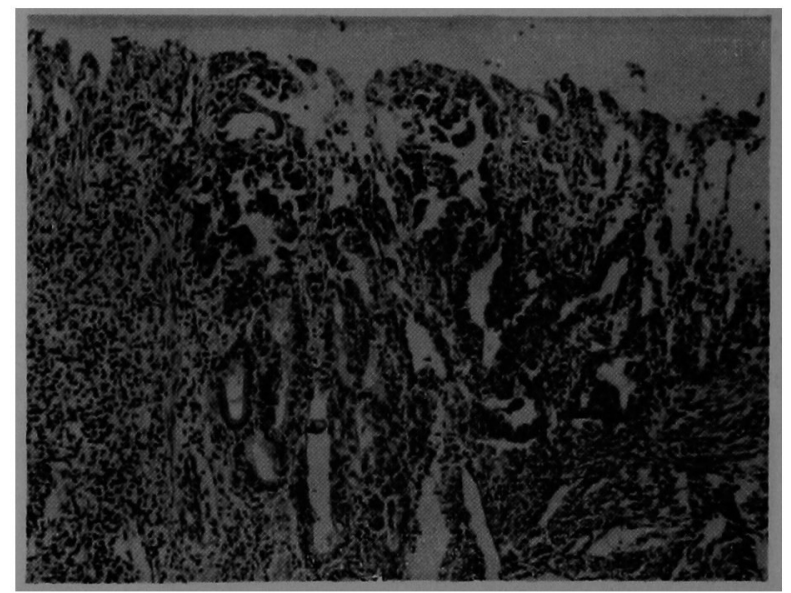

Fig. 29. Photomicrogram of cancer tissue which has widely spread in the gastric mucosa along the margin of the ulcer of this case. $\mathrm{H}$ and $\mathrm{E}$ stain, $\times 100$.

around the ulcers. Although a few of them, that is, those situated somewhat apart from the ulcer margins, appeared to be the lesions which developed on the basis of chronic gastritis as suggested by Konjetzny, ${ }^{10}$ the remaining majority were found in the atypically proliferated mucosae on, or adjacent to, the ulcer margins, and these atypical mucosae were not infrequently accompanied by regenerative process of the epithelium. Moreover, it was particularly noteworthy that some of such cancer foci were connected to the regenerated epithelia by very narrow transitional areas. The latter feature well agrees with the one which Murakami ${ }^{11}$ described as an evidence for carcinogenesis in the regenerated epithelium and fairly suggests that these small cancer foci have developed in relation to epithelial regeneration at the margins of gastric ulcers. Thus, the histopathology of. the small cancer foci 
identified on the ulcer margins or in their vicinities seems to support a well-known hypothesis that the malignant change of gastric ulcer is in most instances a result of pathological regeneration of epithelium which is caused by alternately repeated destruction and regeneration of the mucosa at the margin of the ulcer.,2,12-14

The second fact of interest is the multiplicity of cancer foci as revealed in Cases 2 to 13; in these cases, three to eight separate cancer foci were recognized on and around the margin of a single gastric ulcer and the independency of the foci was confirmed by the technique of serial blocks and, in part, serial sections. Inasmuch as all these cancer foci were limited to the mucosa or only slightly invaded the submucosa, it is unlikely that some of them were the lesions caused by lymphatic metastases from the others. This, together with the fact that in one of the cases (Case 5) a cancer focus was apparently different in histology from the other foci of the same case, may suggest multicentric development of carcinoma around the ulcer margin. The possibility of multicentric carcinogenesis on the basis of pre-existing gastric ulcer was already pointed out by Klein, ${ }^{15}$ Suzuki, ${ }^{16}$ Murakami, ${ }^{11}$ and Majima (one of the present authors). ${ }^{2}$

Thirdly, a special consideration may be required on Cases 14 to 25 in which carcinoma occupied the almost entire or entire circumference of the ulcer margin. Bormann ${ }^{6}$ once claimed that such a case should not be regarded as malignant change of gastric ulcer but as secondary ulceration of carcinoma because it was hardly believable that a cancer focus originating at a point of the ulcer margin spread preferentially along the ulcer margin. Even at present, some pathologists are so strict in judgment of malignant change of gastric ulcers that they exclude such ringshaped lesions from ulcer-carcinomas. However, since some of the above 12 lesions suggested secondary confluence of multiple, separate foci and since, as mentioned above, multicentric development of carcinoma is quite probable, it does not appear unreasonable to conclude that the ring-shaped cancer lesions such as observed in these 12 cases also represent malignant changed gastric ulcers.

On the basis of these histopathologic findings, the authors would strongly support the Hauser's view and insist on the presence of ulcer-carcinoma of the stomach. The clinical data on the 25 cases of this series also seem to be favorable for malignant change of gastric ulcers. In fact, 17 of the 25 cases had preoperative histories of characteristic ulcer symptoms which had started to annoy the patients two to some ten years ago, and some of them actually had gastric ulcers, as manifested by roentgenographic and other studies, for as long as or more than five years. It may be also true, as has been known with the recent advance in the study of early carcinoma of the stomach, that the condition of mucosal cancer can occasionally remain as such for a long period of time without further progress. Accordingly, the precedence of ulcer symptoms to establishment of the diagnosis of carcinoma may not always be sure evidence of malignant change of gastric ulcer. But, a considerably long history of ulcer symptoms, such as lasting for five years or more, in 
a patient of stomach cancer may reasonably be interpreted to suggest that the carcinoma has developed on the basis of a pre-existing gastric ulcer. In support of this, the present series included a number of cases in which the clinical course suggestive of malignant change of gastric ulcer could be followed up for two to six years by repeated X-ray studies. Furthermore, although eight of the present cases were operated on within two years since onset of initial symptoms, of without any symptoms suggestive of gastric ulcer, this fact does not necessarily imply that these were not the cases of ulcer-carcinomas, because gastric ulcer is not infrequently silent.

\section{CONCLUSIONS}

Twenty-five cases with probable early ulcer-carcinomas of the stomach, in which cancer foci were quite small and were confined within the mucosal layer of the ulcer margin or perimarginal areas, were picked up from a total of 2,484 cases of stomach resection for gastric ulcer or carcinoma. The histopathologic study of the specimens and retrospective examination of preoperative histories of these cases gave the results in support of malignant change of gastric ulcers. On the basis of this study, a brief discussion was devoted to the mechanism of carcinogenesis at the margin of gastric ulcer.

\section{References}

1) Hauser, G. Henke-Lubarsch's Hdb. d. spez. path. Anat. u. Hist., 1926, Bd. 4, Ht. $1,439$.

2) Majima, S. Tohoku J. exp. Med., 1955, 62, 53.

3) Majima, S. ibid., 1955, 62, 63.

4) Majima, S., Katami, J., Kurakake, Y. \& Hoshi, N. ibid., 1955, 62, 75.

5) Stromyer, F. Beitr. path. Anat., 1912, 54, 1.

6) Borrmann, R. Henke-Lubarsch's Hdb. d. spez. path. Anat. u. Hist., 1926, Bd. 4, Ht. $1,902$.

7) Mallory, T.B. Arch. Path., 1940, 30, 348.

8) Pack, G.T. Cancer, 1950, 3, 515.

9) Enjoji, M. Fukuoka Acta Med., 1961, 52, 547.

10) Konjetzny, G.E. Der Magenkrebs, Stuttgart, 1938, p. 21.

11) Murakami, T. Acta path. Jap., 1952, 2, 10.

12) Büchner, F. Allgemeine Pathologie, 3rd ed., Munich-Berlin, 1959, p. 248.

13) Kuru, M. Gann, 1953, 44, 47.

14) Tschantz, P.P. Gastroenterologia, 1963, 99, 81.

15) Klein, S.H. Arch. Surg., 1938, 37, 155.

16) Suzuki, Y. Mitt. allg. Path., 1941, 10, 219. 